\title{
First Otoliths/Collagen/Bacterial Cellulose Nanocomposites as a Potential Scaffold for Bone Tissue Regeneration
}

\author{
Gabriel Molina de Olyveira ${ }^{1}$, Daisy Pereira Valido ${ }^{3}$, Ligia Maria Manzine Costa ${ }^{1}$, \\ Plácia Barreto Prata Gois ${ }^{3}$, Lauro Xavier Filho ${ }^{3}$, Pierre Basmaji ${ }^{2}$
}

\footnotetext{
${ }^{1}$ Department of Nanoscience and Advanced Materials, Federal University of ABC, Santo André, Brazil; ${ }^{2}$ Innovatec's-Biotechnology Research and Development, São Carlos, Brazil; ${ }^{3}$ Natural Products Laboratory and Biotechnology, UNIT, Aracaju, Brazil.

Email: gmolyveira@yahoo.com.br
}

Received March 11 ${ }^{\text {th }}$ 2011; revised May $4^{\text {th }}$ 2011; accepted May $15^{\text {th }}, 2011$.

\begin{abstract}
In the present work, we report the first bionanocomposite material formed by otoliths/ collagen/ bacterial cellulose (BC) networks (OCBC). This biomaterial is an osteoinductor or be, stimulates the bone regeneration, enabling bigger migration of the cells for formation of the bone tissue regeneration mainly because nanotolith are rich in minerals considered essential to the bone mineralization process on a protein matrix (otolin). The objective in this study was to analyze the regeneration capacity of bone defects treated with this bionanocomposite. Histological experiments shows bone tissue formation with high regularity, higher osteoblast activity and osteo-reabsorption activities areas. The results suggest the potential for this new biomaterial as a scaffold for bone tissue regeneration.
\end{abstract}

Keywords: Bacterial Cellulose, Natural Composites, Bionanocomposites, Tissue Engineering, Bone Tissue Regeneration

\section{Introduction}

Despite many advances in tissue engineering (TE), scientists still face significant challenges in repairing or replacing soft tissues such as tendons, ligaments, skin, liver, nerve and cartilage to improve the quality of people life. Conventional therapeutic treatments targeted to reconstruct the injured tissues or organs have some limitations such as donor limitations and graft rejections [1]. To meet all the necessary requirements for the success of these approaches, the choice of polymer, design of the matrices and knowledge of the factors affecting cell/tissue-material interactions should be investigated.

The ideal scaffold also requires a desirable mechanical rigidity and a porous 3D structure which can provide maximum integration with cells and body fluids, plus have a nanostructure surface which facilitates the adhesion of cells [1]. In tissue engineering, matrices are developed to support cells, promoting their differentiation and proliferation towards the formation of a new tissue. Such strategies allow for producing hybrid constructs that can be implanted in patients to induce the regeneration of tissues or replace failing or malfunctioning organs. Natural based polymers offer the advantage of being similar to biological macromolecules, which the biological environment is prepared to recognize and deal with metabolically. Owing to their similarity with the extracellular matrix (ECM), natural polymers may also avoid the stimulation of chronic inflammation or immunological reactions and toxicity, often detected with synthetic polymers [2]. Bacterial cellulose (BC) has established to be a remarkably versatile biomaterial and can be used in wide variety of applied scientific endeavours. Due to its unique nanostructure and properties, microbial cellulose is a natural candidate for numerous medical and tissueengineered applications. Moreover, the nanostructure and morphological similarities with collagen make BC attractive for cell immobilization and cell support [3-5].

The application of physical barriers in order to regenerate bone defects was first described by Dahlin et al. [6] The involvement of repair by fibrous union occurs in the bone defect, invasion of fibroblasts in the blood clot. For this to be avoided, one can resort to surgical techniques that prevent the blood clot and/or bone lesion are populated by undesirable cells by application of physical barriers or membranes, thereby facilitating the migration of cells with osteogenic potential. Thus, it is prevented that 
the fibroblasts to colonize the clot before the osteoblasts, which, being more specialized, are slower in its function. [7] Some in vitro studies have been conducted to verify the performance of membranes in the cartilage tissue as flattering to the migration of chondrogenic cells, as occurs in bone tissue [8,9]. Biosynthetic membranes show good acceptance by the body, protecting and aiding the repair of damaged areas by selective permeability, and prevent contamination by microorganisms $[10,11]$. The biosynthetic membrane based on cellulose was used in experiments in dogs trochleoplasty, not interfering in biomechanics and even in the intra-articular [12]. Moreover, it accelerated the initial repair of the trochleoplasty area, showing good integration of newly formed tissue with the adjacent cartilage. However, as a single part, is not effective to promote complete regeneration of articular cartilage [12]. According to Helenius et al. [13], the cellulose membrane obtained from bacteria has good compatibility and has promising potential for use in tissue engineering.

The mimicking of ECM by using natural origin materials has been further attempted using complementary approaches too, in order to improve the performance of these materials. A nano- and microfiber combined starch-based scaffold [14] showed that its unique architecture, being able to support and guide cells, can also provide an ideal structure for cell deposition and organization to be used to bone tissue engineering. Grande et al. [15] fabricated BC-Hap nanocomposites to bone tissue regeneration by the formation of cellulose nanofibrils in the presence of a mineral phase in a static culture. In order to suspend Hap nanoparticles, bacteria culture medium were modified with carboxymethylcellulose (CMC). In vitro biocompatibility and viability was assessed using HEK cells. The pore size and fibre diameter of BC networks are influenced by the water extraction method. Studies reported by Bhattarai et al. [16] and Yang et al. [17] indicate that the pore size and fibre diameter of scaffolds influence the cell growth.

In this work, we report a new bionanocomposite material formed by otoliths/collagen/bacterial cellulose (BC) networks (OCBC). The biomaterial (OCBC) is constituted of some elements constituents of the bones, as collagen (protein) and nano-otoliths, beyond the membrane of bacterial cellulose. Collagen is regarded by many as an ideal scaffold or matrix for tissue engineering as it is the major protein component of the extracellular matrix, providing support to connective tissues such as skin, tendons, bones, cartilage, blood vessels, and ligaments $[18,19]$. In its native environment, collagen interacts with cells in connective tissues and transduces essential signals for the regulation of cell anchorage, migration, proliferation, differentiation, and survival $[19,20]$. Collagen scaffolds, due to their fast degradation, do not allow isomorphous replacement with a newly formed bone. Presumably, due to the stable macro porous structure and slow degradation, the progression and extent of osteogenesis were markedly and significantly higher for silk and RGD-silk scaffolds when compared with collagen scaffolds [20]. Then, BC is our option to be a substrate with collagen and nano-otholits.

Nano-otholits is an osteoinductor or be, stimulates the bone regeneration, enabling bigger migration of the cells for formation of the bone tissue. Otoliths of Cynoscion acoupa are small particles, composed of a combination of a gelatinous matrix and calcium carbonate, present in the ear internal bony fishes and are part of a system which acts as a sensor of depth and balance, so as a detector of sound vibrations. The Cynoscion acoupa is commercialized in all the coast of Brazil. The Cynoscion acoupa of the fish demonstrated to be an important source of collagen too; the membranes of collagens can be gotten from the acid extraction and posterior saline precipitation.

New advances in bone tissue engineering have motivated the search for new materials that are biocompatible with the different bioactive functions which actually occur in live, growing tissues. [21] This biomaterial has potential also as help in others kinds of bone regeneration, of threesomes or small fractures or same cases associated to the osteoporosis. The goal of this study is to produce highly efficacious scaffolds to engineer functional bone tissue with natural bone histological structure and properties for the cure of bone loss in clinical settings.

\section{Experimental Details}

\subsection{Materials}

Bacterial cellulose membranes, $\sim 500 \mathrm{~mm}$ thick, were supplied from Innovatecs-Produtos Biotecnológicos Ltda, Brazil; Otoliths were supplied by VIAFARMA LTDA, Brazil and Collagen were supplied by Sigma Aldrich.

\subsection{Synthesis of Bacterial Cellulose}

Bacterial Cellulose (BC) produced by Gram-negative acetic acid bacteria Gluconacetobacter xylinus can be obtained from the culture medium in the pure 3-D structure consisting of an ultra fine network of cellulose nanofibres (3 - $8 \mathrm{~nm}$ ), highly hydrated (99\% in weight), and displaying higher molecular weight, higher cellulose crystallinity (60\% - 90\%), enormous mechanical strength and full biocompatibility [22].

\subsection{Nano-Otholits Gels}

The material in this study was prepared with $1 \mathrm{~g}$ powder of otolith of Cynoscion acoupa with particle size 60 mesh and addiction $0.25 \mathrm{~g}$ of hydrolyzed collagen, diluted in distilled water. The final product was packaged 
in dishes Petri and sterilized in UV rays (25 min). Subsequently, $1.0 \mathrm{~g}$ of the otoliths was diluted in $100 \mathrm{~mL}$ of distillated water, and the $\mathrm{pH}$ of the compound was assessed by using phmetro Digimed ${ }^{\circledR}$ (São Paulo, SP, Brazil) according to the manufacturer instructions. Stable gel is formulated with a otoliths calcium salt concentration solution. The use of poorly water-soluble salts $\left(\mathrm{CaCO}_{3}\right)$ influences gelatin rate and, consequently, mechanical properties.

\subsection{Bionanocomposite Preparation}

In the present study, we have explored a novel biomaterial, and prepared different bacterial cellulose nanocomposites(BC); 1) Pure BC, 2) BC with collagen and 3) BC/otoliths/collagen. Bacterial cellulose nanocomposite was obtained by immersion of dried bacterial cellulose into collagen and otolith/collagen gels and posterior soft drying at $50^{\circ} \mathrm{C}$ by 12 hours.

\section{Bionanocomposites Characterization}

Scanning Electron Microscopy (SEM)-Scanning electronic microscopy images were performed on a PHILIPS XL30 FEG. The samples were covered with gold and silver paint for electrical contact and to perform the necessary images.

Histological Experiment-The experiment was performed with 20 Wistar rats randomized into two groups, in which a bone defect was inflicted in the tibia. In group 1 (experimental), bone cavities were filled with otoliths nanocomposites [23].

\section{Results and Discussion}

\subsection{Scanning Electronic Microscopy (SEM)}

Bacterial cellulose mats were characterized by SEM. Figure 1 shows, as an example, SEM image of Bacterial cellulose mats.

In order to obtain a bionanocomposite with mechanical properties and an osteoconductive environment that can facilitate cell attachment [24] and to increase in vitro proliferation and differentiation of osteoblastic cells [25] as well as the rapid vascularization and deposition of connective tissue and calcified matrix in vivo, BC/col- lagen/nano-otholits were obtained.

In Figures 2 and 3, scanning electron microscopy (SEM) image of the bacterial cellulose/collagen surface morphology and bacterial cellulose/collagen/otholits nanocomposites is ilustred.

\subsection{Cellulose Bacterial/Otoliths/Collagen Membrane in Vivo Biological Performance}

The Histological sections revealed that the newly formed trabecular bone was denser and the periosteal reabsorptive activity was less conspicuous in the experimental

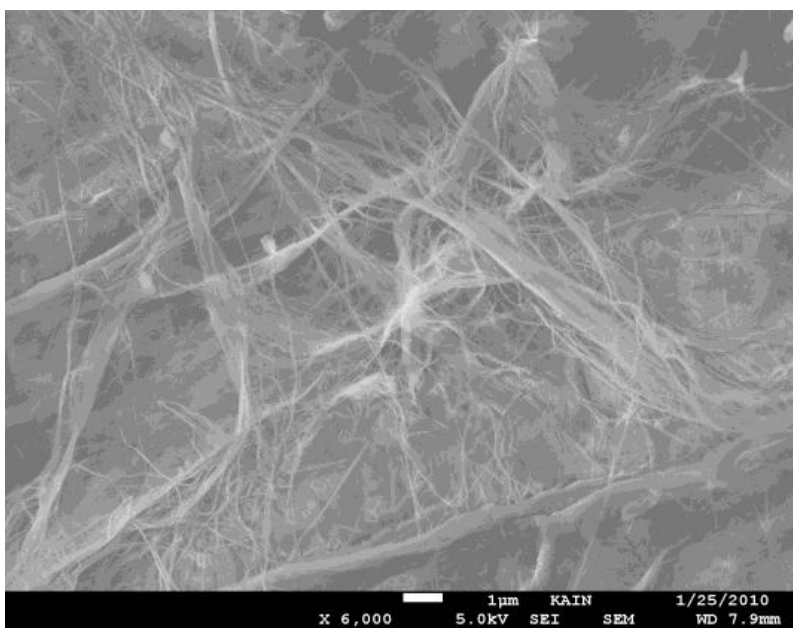

Figure 1. Scanning electron microscopy (SEM) of pure bacterial cellulose.

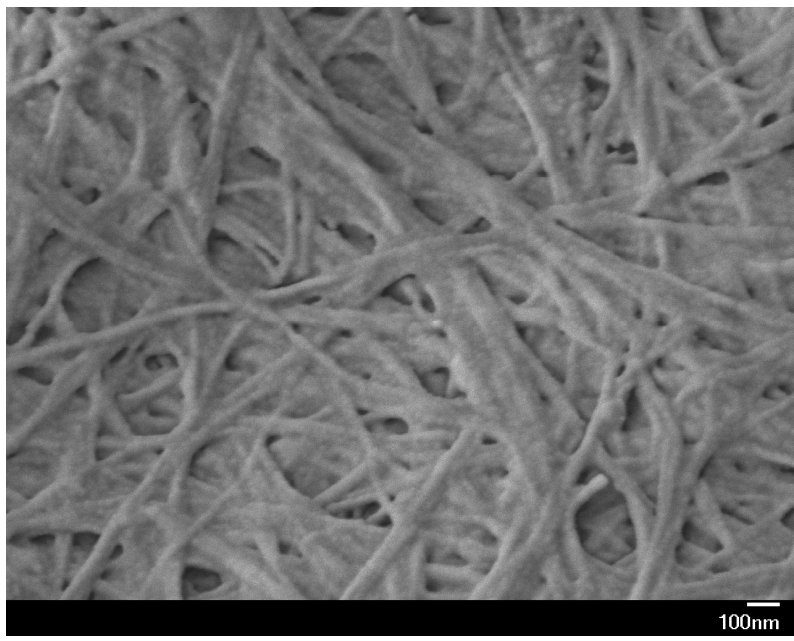

Figure 2. Cellulose bacterial/collagen surface morphology.

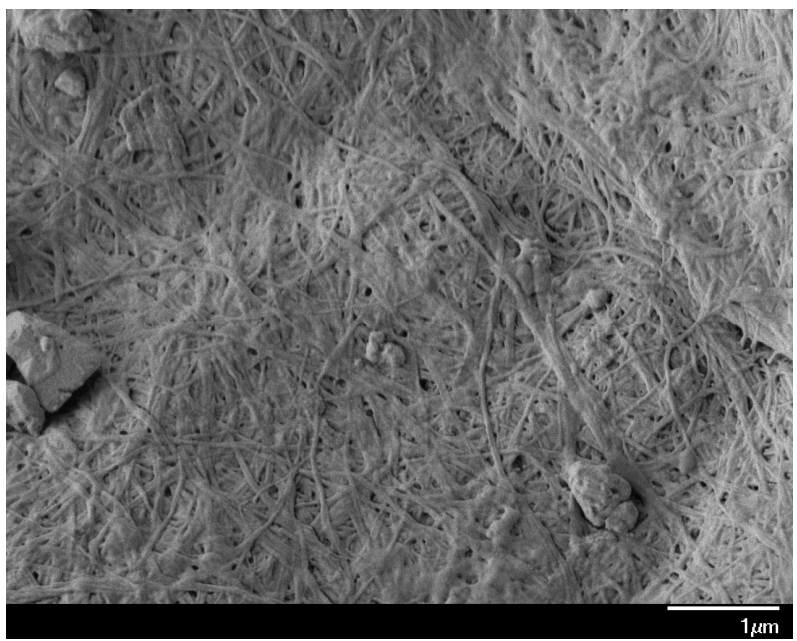

Figure 3. Cellulose bacterial with otoliths/collagen membrane. 


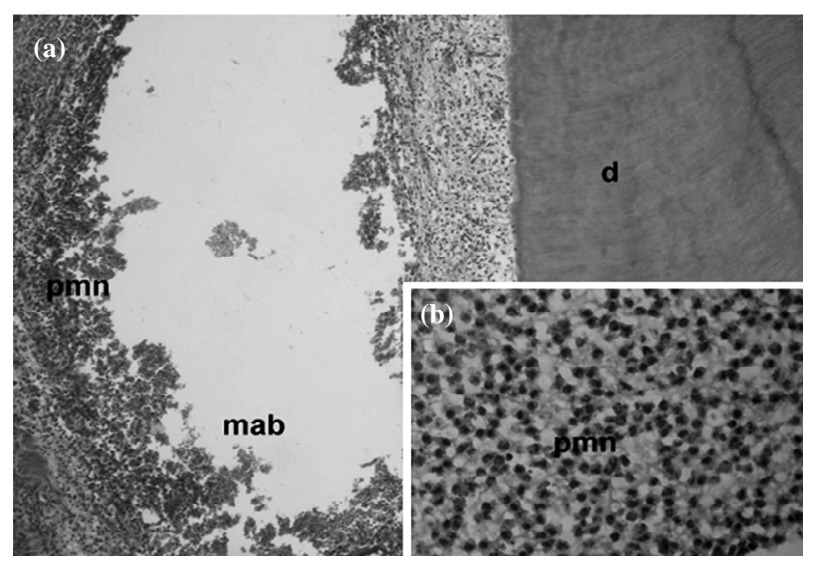

Figure 4. (a) Osteotomized area showing irregular trabecular bone, intertwined aspect and thin thickness; (b) The trabecular were stretching out, in the general form, from a side to other of the bone defect induced artificially, showing osteoblast activity and the periosteum demonstrated moderate degree of fibrosis. Besides, it can be observed areas of intense infiltration of polymorphonuclear neutrophils $(P M N)$ and formation of microabscesses (MAB) in Figure 4(a) and (b).

group (group 1) reported in Figures 4(a) and (b). Biochemical (calcium $\left(\mathrm{Ca}^{2+}\right.$ ) and alkaline phosphatase (Alp) parameters were within normal range. In all the cases the neo formations of trabecular bone was observed, the majority with irregular appearance, intensely intertwined aspect and thin thickness. Besides, it can be observed areas of intense infiltration of polymorphonuclear neutrophils (PMN) and formation of microabscesses (MAB) in Figures 4(a) and (b).

In the experimental group (group1), we observed in the Figures 4(a) and (b), that the bone surface tissue present high regularity and higher osteoblast activity in addition, osteo-reabsorption activities areas is can be observed cleary in Figures 4(a) and (b).

\section{Conclusions}

We report the first otoliths/collagen/cellulose bacterial nanocomposites as a potential scaffold for bone regeneration. The success of subsequent transplantation of the in vitro engineered construct is due to the properties of the materials but also on the osteoprogenitor cell sources. It is expected that the seeded cells will secrete specific ECM components in vitro, to induce proliferation and differentiation into osteoblasts and result in the formation of a new bone in vivo. Otoliths/collagen/CB new scaffolds should be designed for different applications, such as: to induce vascularization; facilitate the deposition of otoliths in predefined regions; guide the regeneration of tissue in certain directions permit the development of different tissues; or inhibit calcification and cell adhesion.
The field is widely open for new creative research- ers in real clinical applications.

\section{REFERENCES}

[1] T. A. Taton, "Nanotechnology: Boning up on Biology," Nature, Vol. 412, No. 6846, 2001, pp. 491-492. doi:10.1038/35087687

[2] B. S. Kim, C. E. Baez and A. Atala, "Biomaterials for Tissue Engineering," World Journal of Urology,Vol. 18, No. 1, 2000, pp. 2-9. doi:10.1007/s003450050002

[3] P. Basmaji, et al. Brazilian patent number: PI0604760-2.

[4] K. Tuzlakoglu, N. Bolgen, A. J. Salgado, et al., "Nanoand Micro-Fiber Combined Scaffolds: A New Architecture for Bone Tissue Engineering,” Journal of Materials Science: Materials in Medicine, Vol. 16, No. 12, 2005, pp. 1099-1104. doi:10.1007/s10856-005-4713-8

[5] W. Czaja, A. Krystynowicz, S. Bielecki, et al., "Microbial Cellulose-the Natural Power to Heal Wounds," Biomaterials, Vol. 27, No. 2, 2006, pp. 145-151. doi:10.1016/j.biomaterials.2005.07.035

[6] C. Dahlin, A. Linde and J. Gottlow, et al., "Healing of Bone Defects by Guided Tissue Regeneration,” Plastic and Reconstructive Surgery, Vol. 81, No. 5, 1998, pp. 672676. doi:10.1097/00006534-198805000-00004

[7] N. L. Macedo, F. S. Matuda, L. G. S. De Macedo et al., "Evaluation of Two Membranes in Guided Bone Tissue Regeneration: Histological Study in Rabbits,” Brazilian Journal of Oral Sciences, Vol. 3, No. 8, 2004, pp. 395400.

[8] E. B. Hunziker, “Articular Cartilage Repair: Basic Science and Clinical Progress. A Review of the Current Status and Prospects,” Osteoarthritis and Cartilage, Vol. 10, No. 6, 2001, pp. 432-463. doi:10.1053/joca.2002.0801

[9] A. Svensson, E. Nicklasson, T. Harrah, et al., "Bacterial Cellulose as a Potential Scaffold for Tissue Engineering of Cartilage,” Biomaterials, Vol. 26, No. 4, 2005, pp. 419431. doi:10.1016/j.biomaterials.2004.02.049

[10] M. Aslan, G. Simsek and E. Dayl, “Guided Bone Regeneration (GBR) on Healing Bone Defects: A Histological Study in Rabbits," Journal of Contemporary Dental Practice, Vol. 5, No. 2, 2004, pp. 114-123.

[11] R. S. Carvalho, D. Nelson, H. Keldernian, et al., "Guided Bone Regeneration to Repair an Osseous Defect," American Journal of Orthodontics and Dentofacial Orthopedics, Vol. 123, No. 4, 2003, pp. 455-467. doi:10.1067/mod.2003.59

[12] L. S. Iamaguti, C. V. S. Brandão, C. H. Pellizzon, et al. “Análise Histológica e Morfométrica do Uso de Membrana Biossintética de Celulose em Trocleoplastia Experimental de Cães,” Pesquisa Veterinária Brasileira, Vol. 28, No. 4, 2008, pp. 195-200.

[13] G. Helenius, H. Bäckdahl, A. Bodin, et al., "In vivo Biocompatibility of Bacterial Cellulose,” Journal of Biomedical Materials Research A, Vol. 76, No. 2, 2006, pp. 431438. doi:10.1002/jbm.a.30570 
[14] C. J. Grande. F. G. Torres, C. M. Gomez, et al., "Development of Self-Assembled Bacterial Cellulose-Starch Nanocomposites," Materials Science and Engineering C, Vol. 29, No. 4, 2009, pp. 1098-1104.

doi:10.1016/j.msec.2008.09.024

[15] C. J. Grande, F. G. Torres, C. M. Gomez, et al., "Nanocomposites of Bacterial Cellulose/Hydroxyapatite for Biomedical Applications,” Acta Biomaterialia, Vol. 5, No. 5, 2009, pp. 1605-1615. doi:10.1016/j.actbio.2009.01.022

[16] S. J. Bhattarai, N. Bhattarai, H. K. Yi, et al., "Novel Biodegradable Electrospun Membrane: Scaffold for Tissue Engineering," Biomaterials, Vol. 25, No. 13, 2004, pp. 2595-2602. doi:10.1016/j.biomaterials.2003.09.043

[17] S. Yang, K. F. Leong, Z. Du, et al., “The Design of Scaffolds for Use in Tissue Engineering Part I Traditional Factors," Tissue Engineering, Vol. 7, No. 6, 2001, pp. 679-689. doi:10.1089/107632701753337645

[18] G. P. Chen, T. Ushida and T. Tateishi, "Hybrid Biomaterials for Tissue Engineering: A Preparative Method for PLA or PLGA-Collagen Hybrid Sponges,” Advanced Materials, Vol. 12, No. 6, 2000, pp. 455-467. doi:10.1002/(SICI)1521-4095(200003)12:6<455::AID-A DMA455>3.0.CO;2-C

[19] M. Geiger, R. H. Li and W. Friess, "Collagen Sponges for Bone Regeneration with rhBMP-2,” Advanced Drug Delivery Reviews, Vol. 55, No. 12, 2003, pp. 1613-1629. doi:10.1016/j.addr.2003.08.010

[20] L. Meinel, R. Langer, G. Vunjak-Novakovic, et al., "Bone Tissue Engineering Using Human Mesenchymal Stem
Cells: Effects of Scaffold Material and Medium Flow,” Annals of Biomedical Engineering, Vol. 32, No. 1, 2004, pp. 112-122. doi:10.1023/B:ABME.0000007796.48329.b4

[21] F. Korkusuz, P. Korkusuz and V. Hasirci, “In Vivo Tissue Engineering of Bone Using Poly(3-Hydroxybutyric Acidco-3-Hydroxyvaleric Acid) and Collagen Scaffolds," Tissue Engineering, Vol. 10, No. 7-8, 2004, pp. 1234-1250. doi:10.1089/ten.2004.10.1234

[22] D. Klemm, B. Heublein, H. P. Fink, et al., "Cellulose: Fascinating Biopolymer and Sustainable Raw Material A,” Angewandte Chemie International Edition, Vol. 44, No. 22, 2005, pp. 3358-3393. doi:10.1002/anie.200460587

[23] D. P. Valido and T. S. Bastos, R. L. C. Albuquerque- Júnior, et al., "Estudo Preliminar da Utilização de Otólitos de Cynoscion Acoupa Sobre o Processo de Neoformação Óssea em Ratos,” Jornal Brasileiro de Patologia e Medicina Laboratorial, Vol. 46, No. 4, 2010, pp. 315-322. doi:10.1590/S1676-24442010000400009

[24] V. Luginbuehl, E. Wenk, A. Koch, et al., "Insulin-Like Growth Factori-Releasing Alginate-Tricalciumphosphate Composites for Bone Regeneration,” Pharmaceutical Research, Vol. 22, No. 6, 2005, pp. 940-950. doi:10.1007/s11095-005-4589-9

[25] Y. J. Seol, J. Y. Lee, Y. J. Park, et al., "Chitosan Sponges as Tissue Engineering Scaffolds for Bone Formation," Biotechnology Letters, Vol. 26, No. 13, 2004, pp. 10371041. doi:10.1023/B:BILE.0000032962.79531.fd 